Review

\title{
Drosophila melanogaster Responses against Entomopathogenic Nematodes: Focus on Hemolymph Clots
}

\author{
Alexis Dziedziech, Sai Shivankar and Ulrich Theopold * \\ Department of Molecular Biosciences, The Wenner-Gren Institute (MBW), Stockholm University, \\ 10691 Stockholm, Sweden; alexis.dziedziech@su.se (A.D.); sai.krishnamoorthy@su.se (S.S.) \\ * Correspondence: uli.theopold@su.se; Tel.: +46-8164181
}

Received: 10 December 2019; Accepted: 14 January 2020; Published: 19 January 2020

check for updates

\begin{abstract}
Several insect innate immune mechanisms are activated in response to infection by entomopathogenic nematodes (EPNs). In this review, we focus on the coagulation of hemolymph, which acts to stop bleeding after injury and prevent access of pathogens to the body cavity. After providing a general overview of invertebrate coagulation systems, we discuss recent findings in Drosophila melanogaster which demonstrate that clots protect against EPN infections. Detailed analysis at the cellular level provided insight into the kinetics of the secretion of Drosophila coagulation factors, including non-classical modes of secretion. Roughly, clot formation can be divided into a primary phase in which crosslinking of clot components depends on the activity of Drosophila transglutaminase and a secondary, phenoloxidase (PO)-dependent phase, characterized by further hardening and melanization of the clot matrix. These two phases appear to play distinct roles in two commonly used EPN infection models, namely Heterorhabditis bacteriophora and Steinernema carpocapsae. Finally, we discuss the implications of the coevolution between parasites such as EPNs and their hosts for the dynamics of coagulation factor evolution.
\end{abstract}

Keywords: insect immunity; innate immunity; hemocytes; secretion; nematodes; coagulation; clotting; phenoloxidase; transglutaminase

\section{Introduction}

\subsection{Two Key Immune Pathways Are Dispensable in a Drosophila EPN Model}

The life cycle of entomopathogenic nematodes (EPNs) requires that they breach epithelial barriers and create wounds in order to reach the hemolymph, where they complete their life cycle. Once inside their insect hosts, many EPN species release symbiotic pathogenic bacteria of the genera Photorhabdus or Xenorhabdus [1]. To varying extents, both the nematodes and their bacteria contribute to the success of EPN infections. Although EPN infections are known to induce immune factors, such as antimicrobial peptides, the two major immune pathways involved (imd and Toll) are shown to be dispensable for EPN control upon infection of Drosophila melanogaster with Heterorhabditis bacteriophora/Photorhabdus luminescens [2].

\subsection{A Search for Alternative Immune Reactions against EPNs}

Alternative potentially protective/immune responses against EPNs, which were identified in Drosophila and other insects comprise (see Box 1 for an overview of the reactions), (1) the formation of hemolymph clots at the wound site where nematodes enter (Box 1 and this review) and (2) encapsulation of nematodes [3-5]. The immune response of the host may target the symbiotic bacteria of the nematode 
through many potential mechanisms; however, the invading bacteria have often developed their own virulence factors which render the host's response futile. Such responses on behalf of the host include (1) antimicrobial peptides [6,7], (2) phenoloxidase (PO) activity [8,9] (3) phagocytosis [10] and (4) nodulation i.e., the formation of aggregates, which contain immune effector cells (hemocytes [11]) and bacteria [12]. Encapsulation and nodule formation involve the release of extracellular components from hemocytes and lead to entrapment of larger objects, such as wasp eggs and nematodes (capsules) or larger numbers of bacteria (nodules). Encapsulation and nodule formation were functionally likened to the formation of granulomas in mammals [13]. At the cellular level, hemolymph coagulation, encapsulation and nodule formation show several similarities including extensive degranulation of hemocytes, the formation of an extracellular matrix and ultimately the conversion of prophenoloxidase (PPO) into its active form, PO [14]. PO (see also Box 1) is part of a multifunctional biochemical pathway with cytotoxic and crosslinking activity, which ultimately leads to the formation of melanin. Whether the similarities at the cellular level extend to the molecular mechanism remains to be determined. In this review, we summarize work on EPN infections in the model organism Drosophila melanogaster and a few additional insects, with focus on the coagulation- and the PPO-activating system. We also describe the Drosophila coagulation system in an evolutionary context in light of recent findings.

Box 1. Drosophila immune responses [15].

Epithelial barriers: epithelial barriers including the cuticle and the gut peritrophic membrane prevent most opportunistic organisms as well as many other microorganisms from gaining access to their insect hosts.

Hemolymph coagulation/clotting: at epithelial breaches, hemolymph components including soluble and hemocyte-derived factors form a matrix (clot) composed of a fibrous or gelatinous network, which seals the wound site. Clot components may be linked covalently (in Drosophila initially by transglutaminase and subsequently by phenoloxidase) or non-covalently (in many non-insect arthropods, see main text) and provide a substrate for further wound healing $[16,17]$. Coagulation helps to stop bleeding and to prevent entry of microbial intruders [18].

Antimicrobial peptides (AMPs): AMPs are expressed either constitutively or (in most cases) induced upon infection. They kill microbial intruders alone or in combination. AMPs as well as many molecules involved in other immune reactions are induced by two major pathways (imd and Toll) as well as through stress-related paths (JNK and JAK/STAT).

Phagocytosis: small microbial intruders are engulfed by a specialized class of hemocytes (plasmatocytes), which are akin to mammalian macrophages.

Nodule formation: although less studied in Drosophila, nodule formation in other insect is a reaction against larger numbers of bacteria, which exceed the phagocytic capacity of individual plasmatocytes. It leads to the formation of granuloma-like structures, which immobilize and kill bacteria.

Encapsulation: larger intruders, such as wasp eggs, are encapsulated initially by plasmatocytes and at later stages by lamellocytes. Lamellocytes are large flat cells, which are absent in naïve larvae and differentiate upon wasp infestation or wounding in hematopoietic organs or through trans-differentiation from plasmatocytes $[19,20]$.

The phenoloxidase-activating system (PAS): the PAS involves a close collaboration between an extracellular proteolytic cascade, which is activated either by exogenous microbial elicitors or endogenous damage signals and hemocyte-derived prophenoloxidase (PPO). In Drosophila, two PPOs (PPO1 and PPO2) are harbored by a specialized class of hemocytes (crystal cells [21]), while a third one (PPO3) is produced by lamellocytes [22].

\section{Hemolymph Coagulation in Non-Insect Arthropods}

Due to their highly variable environments, coagulation systems in arthropods show a high level of variation [23] despite some coagulation factors (transglutaminase) and some coagulation factor domains (discoidin domain) being found across taxa [18]. Much of our knowledge of hemolymph coagulation stems from several model systems which were chosen due to their biochemical/genetic accessibility or because of their commercial interest. One such model is the horseshoe crab, an ancient arachnid in which coagulation involves activation of a serine protease cascade, known to be extremely sensitive to microbial elicitors such as lipopolysaccharides (LPS) from Gram-negative bacteria [24]. Ultimately, activation of the cascade leads to the cleavage of soluble coagulogen into insoluble coagulin, which forms non-covalently linked homopolymers [24,25]. Additional strengthening of the clot matrix occurs via transglutaminase (TG)-dependent crosslinking of proline-rich proteins (proxins, [26]). 
Proxins are also present on hemocyte surfaces, ensuring hemocyte incorporation into the clot [26]. All clot components in horseshoe crabs, including TG, are present in their hemocytes and are released upon stimulation by LPS [24,27]. This is in contrast to crustaceans, such as crayfish and lobster, in which TG that is derived from hemocytes or other tissues directly polymerizes plasma clottable proteins into clot fibers without the need for a proteolytic cascade $[28,29]$. Crayfish clottable protein shows no similarity to horseshoe crab coagulogen or mammalian fibrinogen but is instead related at the sequence level to insect vitellogenin with which it shares the presence of a von Willebrand factor D domain (vWF), which is common in mammalian coagulation factors [29,30]. In addition to TG-mediated coagulation, crayfish PPO is released from hemocytes and subsequently activated into phenoloxidase (PO) by a microbially induced proteolytic cascade [28,29]. Both TG and PPO lack classical signal peptides and are therefore released via non-classical secretion (NCS, [24,29]). In these arthropods, it is unknown whether TG and PPO are released simultaneously or at different time points during the coagulation reaction and whether this is mediated by different mechanisms of NCS.

\section{Hemolymph Coagulation in Insects}

Similar to crayfish, insect coagulation involves an interction between soluble hemolymph and hemocyte-derived components $[15,18,31]$. Earlier biochemical studies identified several hemolymph proteins in the clot, including the lipid carrier lipophorin and hemocytin, which shares several domains with vWF [31,32]. Invariably, most insect clots eventually melanize, indicating the presence of PO. Isolation of Drosophila clots confirmed the presence of lipophorin and the hemocytin homolog hemolectin in the clot matrix, as well as one of three Drosophila phenoloxidases (PPO2, [33]). Proteins newly identified as Drosophila coagulation factors using targeted proteomics and molecular genetics, included: the less-conserved fondue: a coagulation factor released from the fat body; tiggrin: a muscle attachment protein; Eig71eE: a salivary gland mucin [33,34]; hemomucin: a hemocyte surface protein [35]; glutactin: a basement membrane component produced by the fat body [36] and imaginal-disc growth factor 3, Idgf3: a protein with similarity to chitinase-like proteins (see Appendix A and text below [37]). Finally, a combination of inhibitor and genetic studies as well as bioinformatics showed that the secreted form of the only Drosophila TG member, a homolog of factor XIIIa, additionally contributes to clot formation [38]. The present view of Drosophila coagulation is that initially a clot forms upon wounding, although it is unclear whether this requires TG, as is the case in crayfish or whether TG acts on already existing (clotted) aggregates. However, it was shown that TG knockdown reduces clot formation and bacterial entrapment in flies, [38] as does factor XIIIa in humans [39]. After the clot seals the wound and captures bacteria preventing further dissemination, crystal cells [40] in the clot release PPO2 contributing additional bactericidal activity, further crosslinking of the clot matrix and eventually melanization [41,42]. In essence, clot formation in Drosophila larvae can be divided into an initial phase in which crosslinking depends on TG and a subsequent phase in which PO further crosslinks and hardens the clot. To fully appreciate the coordination between the two phases, it is essential to understand the release of the two key enzymes transglutaminase and PO from hemocytes and the recruitment and activation in clots to then further understand their mechanism of action against pathogenic threats.

\section{Non-Classical Secretion (NCS) of Drosophila Coagulation Factors}

Naïve Drosophila larvae contain two types of hemocytes: (1) plasmatocytes, which combine the activities of mammalian macrophages and granulocytes through their ability to phagocytose and release hemocyte coagulation factors and (2) crystal cells (CC). As their name indicates, crystal cells harbor several crystals, which contain PPO2. A second PO (PPO1) is located in the cytosol. The third type of hemocytes (lamellocytes) differentiate as a response towards larger intruders, such as wasp eggs, and upon wounding. Lamellocytes are crucial players during encapsulation and produce their own PO (PPO3). Recently, in order to understand two important proteins secreted using NCS, we used GFP-tagged versions of coagulation factors, namely PPO2 and TG. We showed that hemocyte-derived 
TG stays within the vicinity of hemocytes that are trapped in the clot, similar to what was found in horseshoe crab clots [24,41].

In contrast, ubiquitously expressed TG outlines the clot fibers, where it aids in hardening the clot matrix using fondue as substrate $[34,38,42,43]$. While hemocyte-TG had been previously shown to be targeted to recycling endosomes and released by exosomes [44,45], the mode of NCS remains to be determined for TG found in clot fibers but may involve cell rupture at wound sites or a form of compound secretion. Taken together, it appears that Drosophila TG combines the activity of crayfish and horseshoe crab TG by acting both as a clot crosslinker and by covalently trapping hemocytes in the clot matrix $[41,42]$.

In contrast to hemocyte-TG, PPO2 was found to be released through rupture of crystal cells which subsequently leads to the dissolution of its crystals within the clot where it acts both as a bactericide and as a crosslinker, in addition to TG [41]. This demonstrates that Drosophila hemocytes use two distinct modes of NCS for the release of TG and PPO2 respectively: exosomes for TG and cell rupture for PPO2 (see Figure 1B, plasmatocyte and crystal cell, lower panel). In addition, TG-dependent crosslinking precedes PPO2 activation, which requires CC rupture, dissolution of crystals and PPO activation [41]. These recent findings lead to a greater appreciation of NCS and the orchestration of coagulation factor secretion.

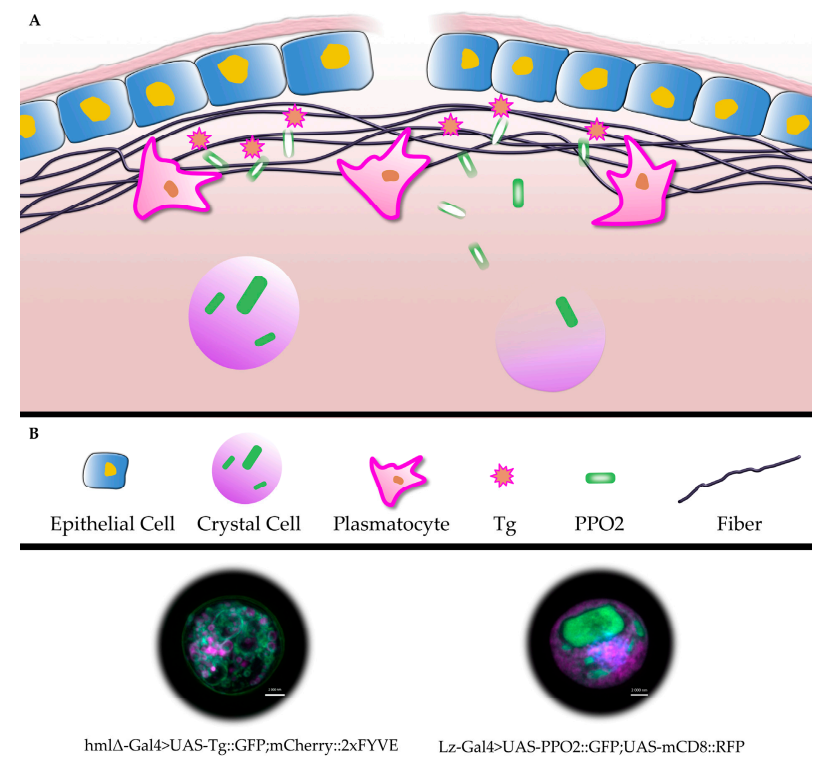

Figure 1. Schematic representation of clot formation in Drosophila larvae (A): structural components of the fibers (Fondue) are cross-linked, initially by transglutaminase and subsequently by phenoloxidase. (B) shows a key to the schematic as well as a plasmatocyte (lower part, inset to the left, with GFP-tagged transglutaminase) and a crystal cell (inset to the right, with GFP-tagged PPO2 in crystalline structures, nuclear staining with 4',6-diamidino-2-phenylindole (DAPI), note that PPO2-containing crystals dissolve after release from crystal cells, indicated by a lighter shading [41] see text for further details).

\section{Drosophila Clots Protect against EPNs}

When mutants or knockdown lines for coagulation factors were exposed to EPNs, some but not all were shown to have a protective effect (see Appendix A for details). When the combination Heterorhabditis bacteriophora/Photorhabdus luminescens was used, knockdowns and mutants for Fondue, glutactin, Idgf3, Eig71Ee and TG but not others (Hml, tiggrin, Hmu, Fbp1) displayed an increase in mortality $[36,38,46]$. Often the effects observed with EPNs were more significant than upon wounding [47] indicating that (1) coagulation shows some level of redundancy, for example by involving lipophorins/hexamerins and (2) some coagulation factors may be more relevant for immunity than for wound closure and healing [48] perhaps by modulating coagulation to protect against a given 
EPN. The latter aspect is strengthened by the fact that in addition to coagulation factors, a protective function of known immune molecules was found during EPN infections. These include immune recognition molecules such as a member of the Gram-negative binding protein family (GNPB3-like), a peptidoglycan receptor (PGRP-LF) and most notably, a member of the thioester-containing proteins, which are homologs of complement factors [36]. In mammals, a close collaboration between coagulation and complement was observed [49,50], and in insects, TEPs are known to intersect with different immune responses, including the PPO-activating system [51-53]. A role for all three Drosophila phenoloxidases was shown in the Steinernema/Xenorhabdus model (Table A1 in Appendix A) [9], while upon infection with Heterorhabditis/Photorhabdus, a mutant which lacks functional crystal cells (Black cell: Bc) and one that lacks an active PPO-activating protease (spn7) showed comparable mortality to controls (Table A1 and [38]). This indicates that even various aspects of clot formation may be of different importance depending on which EPN is studied (Figure 2A,B). In the case of Steinernema carpocapsae, a specific inhibitor (sc-spn6, Figure 2B [54]), inhibits PPO recruitment to the clot and the clot's maturation, rendering the clot ineffective at preventing nematode entry. As a consequence of failed recruitment to the clot, PO activity in the presence of sc-spn6 is instead enriched in the hemolymph. We hypothesize that upon infection with $S$. carpocapsae, PO activity contributes to the host response in the hemolymph after nematode entry, while PO's contribution to the response against $H$. bacteriophora is restricted to the clot.

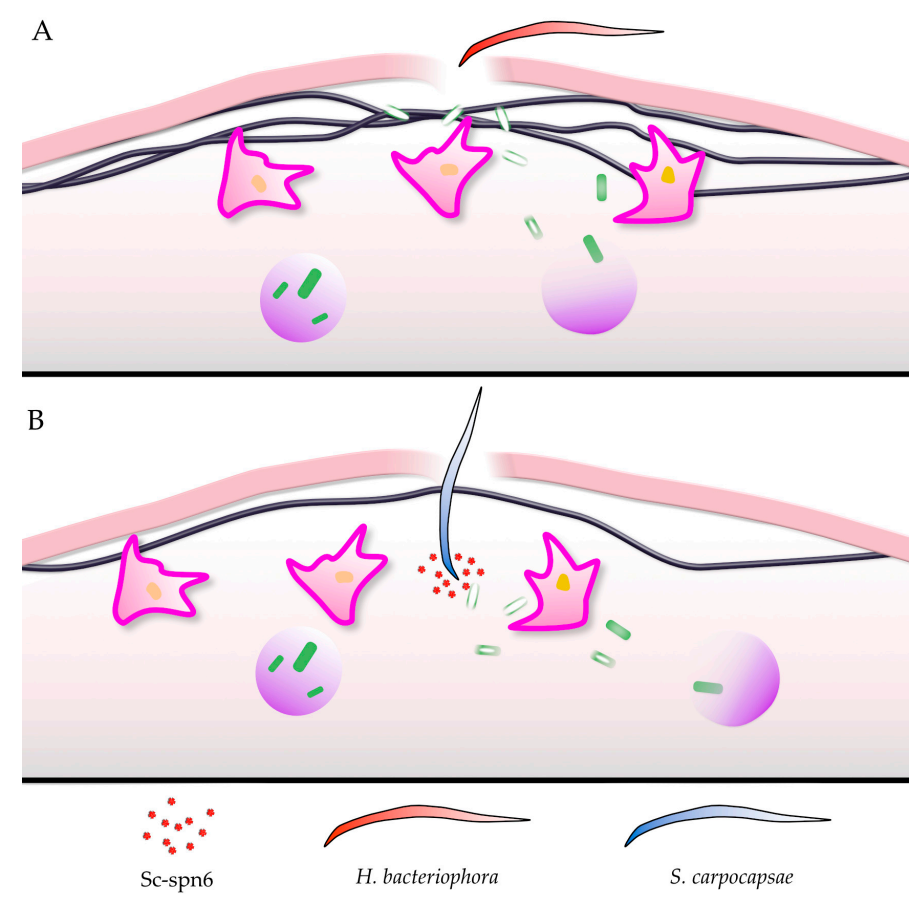

Figure 2. Heterorhabditis bacteriophora (A) and Steinernema carpocapsae (B) use different strategies to invade Drosophila larvae. Of key importance is that the Steinernema serpin Sc-spn6 prevents the association of phenoloxidase with the growing hemolymph clot, thereby reducing clot formation (see text for further details). The key indicates EPN species and Sc-spn6 found in S. carpocapsae.

\section{Other Immune Factors-Eicosanoids as Mediators of Anti-EPN Responses}

An essential biochemical class of immune mediators with relevance during EPN infections are eicosanoids [55]. In mammals, the first step in the production of eicosanoids involves the release of lipids from cell membranes by phospholipase A2 (PLA2). Symbiotic bacteria from EPN complexes, Photorhabdus and Xenorhabdus, were shown to inhibit PLA2 leading to immune suppression in lepidopteran insect hosts [55-57]. Supporting the importance of insect eicosanoids during EPN infections, an effect of knocking down a Drosophila PLA2 was shown [46]. The remaining part of the 
synthetic pathway remained elusive since using the Basic Local Alignment Search Tool prevailed no obvious homologs for cyclooxygenases or lipoxygenases that could be identified in insect genomes. Still, biochemical evidence pointed towards related paths $[46,55]$ and more recently, advanced bioinformatics and genetic evidence identified novel genes involved in eicosanoid production and novel key lipid mediators in Drosophila and the mosquito, Anopheles gambiae [58-60]. Functional analysis confirmed the genes' involvement in regulating inflammatory reactions in Drosophila as well as in hemocyte recruitment and immune priming upon Plasmodium infection in Anopheles. These genes and their Drosophila homologs will be interesting to evaluate in EPN models, particularly in regard to their effects on host hemocytes, clot formation and their potential for immune priming.

\section{Moving beyond Insects-How Evolution Shapes Clot Formation}

Although insects with their open circulatory system have a much-reduced risk of thrombus formation-one of the important adverse side effects of coagulation-clot formation in insects is still tightly regulated and limited to the proximity of wounds and nematode entry sites, leading to a compartmentalization of the hemolymph. This division between the open circulatory system and the coagulation region allows hemocytes to be trapped in the clot matrix while preventing their activation in other localities. Similarly, antibacterial (lysozyme) and PO activity are enriched at wound sites [61]. In addition, PO activity is more durable when microbial elicitors are co-injected at wound sites [61], an observation in line with the dual function of clots during hemostasis and immunity. The relative importance of microbial elicitors (microbe-associated molecular patterns, MAMPs) versus internal signals (damage-associated molecular patterns DAMPs, [62]) may differ between insects. For example, clots from mosquitoes and flies show a substantially more localized pattern of melanization, often associated with cell fragments in comparison to a more diffuse pattern in clots from two lepidopteran species $[63,64]$. One damage-associated mechanism and a possible explanation for localized melanization is the release of microparticles from hemocytes which-similar to platelet microparticles - are pinched off from hemocyte filopodia and therefore expose negatively charged phospholipids (phosphatidylserine, PS) on their surface [32,65]. Platelet PS increases the activity of coagulation factors, which assemble on the surface of microparticles. In Drosophila, externally added PS acts as a more potent activator of PO activity than microbial elicitors and may thus have an equivalent function to mammalian PS, which confers increased procoagulant activity to microparticle-bound coagulation factors [66].

Hemolymph coagulation and blood coagulation thus serve to both seal wounds and-at least in many cases-prevent dissemination of microbial intruders from the wound site. One central coagulation factor that is functionally conserved in both flies and humans is TG (factor XIIIa in humans), which serves to crosslink clot proteins and to immobilize bacteria in the clot $[38,39,67]$. We propose that in the Heterorhabditis/Photorhabdus system, the primary protective effect of coagulation lies in preventing nematode entry in the first place. The clot's protective effect is circumvented by other EPNs where effective coagulation is inhibited, for example in Steinernema carpocapsae where sc-spn6 [54] inhibits recruitment of PO to the clot and thus proper clot maturation. In this way, EPN-host interactions are part of a classical evolutionary race, where the EPNs target different aspects of host behavior, physiology and immunity, and the insect hosts, in turn, adapt via different anti-parasitic pathways. One such example is the balance between the initial phases of coagulation and the subsequent melanization [54,68]. If one accepts the clot's dual function during hemostasis and immunity, a hypercoagulatory phenotype may provide an evolutionary advantage during phases of increased risk of injury or infection via epithelial surfaces. In mammals, the evolutionary advantages of a hypercoagulatory phenotype have to be balanced against the risk of tissue damage during sepsis and microvascular thrombosis, in other words, there are trade-offs between both functions [69]. The balance between a hemostatic and an immune role will be influenced by different environments and by changes in the environment during evolution both at the macro- and microevolutionary scale. For example, it was proposed that introgression of a hypercoagulatory phenotype from Neanderthal genomes into human genomes may 
have conferred improved protection against wounds/infections, which in an urban environment is outweighed by an increased risk of cardiovascular diseases [70]. Similarly, despite the protective effect of insect PO against some EPNs, tissue damage is often a negative consequence of PO activity and it therefore must be tightly controlled [31,32]. In addition to the physical environment, coevolution with potential parasites will shape $\mathrm{PO}$-activation and coagulation systems in insects and mammals, respectively. For both groups, an evolutionary perspective may thus help us to appreciate the darker side of hemostatic defects as a protective convergently evolved trade-off response against intruders, such as nematodes $[69,70]$.

Author Contributions: The following authors contributed to this review in the following ways: conceptualization, all authors; writing original draft preparation, U.T. and A.D.; writing - review and editing, all authors; visualization, S.S. and A.D.; funding acquisition, U.T. All authors have read and agreed to the published version of the manuscript.

Funding: The authors' work was supported by the Swedish Research Council (VR-2010-5988 and VR 2016-04077) and the Swedish Cancer Foundation (CAN 2010/553 and CAN 2013/546).

Acknowledgments: We would like to thank Stina Höglund and the Imaging facility at Stockholm University for support with all aspects of microscopy. We would also like to thank Allison Shan and Roger Karlsson for their critical thoughts and feedback.

Conflicts of Interest: The authors declare no conflict of interest.

\section{Appendix A}

Table A1. Drosophila genes tested for their effects upon infection with EPNs (+: effects were observed; -: no effects; Fb: effects upon knockdown in fat body; Hc: effects upon knockdown in hemocytes).

\begin{tabular}{cccc}
\hline Gene & Effect on EPNs & EPN Used & References \\
\hline imd & - & Heterorhabditis/Photorhabdus & {$[2]$} \\
T1 & - & Heterorhabditis/Photorhabdus & {$[2]$} \\
Transglutaminase & + & Heterorhabditis/Photorhabdus & {$[38]$} \\
Tiggrin & - & Heterorhabditis/Photorhabdus & {$[46]$} \\
Fondue & $+(\mathrm{Fb})$ & Heterorhabditis/Photorhabdus & {$[46]$} \\
Eig71Ee & $+(\mathrm{Hc})$ & Heterorhabditis/Photorhabdus & {$[46]$} \\
Fbp1 & - & Heterorhabditis/Photorhabdus & {$[46]$} \\
Hemomucin & - & Heterorhabditis/Photorhabdus & {$[46]$} \\
Hemolectin & - & Heterorhabditis/Photorhabdus & {$[38]$} \\
GNBP-like 3 & + Fb) & Heterorhabditis/Photorhabdus & {$[36]$} \\
PGRP-LF & + & Heterorhabditis/Photorhabdus & {$[36]$} \\
TEP3 & + & Heterorhabditis/Photorhabdus & {$[36]$} \\
Glutactin & + Hc) & Heterorhabditis/Photorhabdus & {$[36]$} \\
Idgf3 & + & Heterorhabditis/Photorhabdus & {$[37]$} \\
CG 14507 (PLA2) & + & Heterorhabditis/Photorhabdus & {$[46]$} \\
PPO1 & + & Steinernema/Xenorhabdus & {$[9]$} \\
PPO2 & + & Steinernema/Xenorhabdus & {$[9]$} \\
PPO3 & + & Steinernema/Xenorhabdus & {$[9]$} \\
Bc & - & Heterorhabditis/Photorhabdus & {$[38]$} \\
Sp7 (PPO activation) & - & Heterorhabditis/Photorhabdus & {$[38]$} \\
\hline
\end{tabular}

\section{References}

1. Castillo, J.C.; Reynolds, S.E.; Eleftherianos, I. Insect immune responses to nematode parasites. Trends Parasitol. 2011, 27, 537-547. [CrossRef]

2. Hallem, E.A.; Rengarajan, M.; Ciche, T.A.; Sternberg, P.W. Nematodes, bacteria, and flies: A tripartite model for nematode parasitism. Curr. Biol. 2007, 17, 898-904. [CrossRef]

3. Peters, A.; Ehlers, R.U. Encapsulation of the entomopathogenic nematode Steinernema feltiae in Tipula oleracea. J. Invertebr. Pathol. 1997, 69, 218-222. [CrossRef] 
4. Ebrahimi, L.; Niknam, G.; Dunphy, G.B. Hemocyte responses of the Colorado potato beetle, Leptinotarsa decemlineata, and the greater wax moth, Galleria mellonella, to the entomopathogenic nematodes, Steinernema feltiae and Heterorhabditis bacteriophora. J. Insect. Sci. 2011, 11, 75. [CrossRef]

5. Anderl, I.; Vesala, L.; Ihalainen, T.O.; Vanha-Aho, L.M.; Ando, I.; Ramet, M.; Hultmark, D. Transdifferentiation and Proliferation in Two Distinct Hemocyte Lineages in Drosophila melanogaster Larvae after Wasp Infection. PLoS Pathog. 2016, 12, e1005746. [CrossRef] [PubMed]

6. Binda-Rossetti, S.; Mastore, M.; Protasoni, M.; Brivio, M.F. Effects of an entomopathogen nematode on the immune response of the insect pest red palm weevil: Focus on the host antimicrobial response. J. Invertebr. Pathol. 2016, 133, 110-119. [CrossRef] [PubMed]

7. Pena, J.M.; Carrillo, M.A.; Hallem, E.A. Variation in the susceptibility of Drosophila to different entomopathogenic nematodes. Infect. Immun. 2015, 83, 1130-1138. [CrossRef] [PubMed]

8. Whitten, M.M.A.; Coates, C.J. Re-evaluation of insect melanogenesis research: Views from the dark side. Pigment Cell Melanoma Res. 2017, 30, 386-401. [CrossRef]

9. Cooper, D.; Wuebbolt, C.; Heryanto, C.; Eleftherianos, I. The prophenoloxidase system in Drosophila participates in the anti-nematode immune response. Mol. Immunol. 2019, 109, 88-98. [CrossRef]

10. Brivio, M.F.; Mastore, M.; Nappi, A.J. A pathogenic parasite interferes with phagocytosis of insect immunocompetent cells. Dev. Comp. Immunol. 2010, 34, 991-998. [CrossRef]

11. Honti, V.; Csordas, G.; Kurucz, E.; Markus, R.; Ando, I. The cell-mediated immunity of Drosophila melanogaster: Hemocyte lineages, immune compartments, microanatomy and regulation. Dev. Comp. Immunol. 2014, 42, 47-56. [CrossRef] [PubMed]

12. Sadekuzzaman, M.; Park, Y.; Lee, S.; Kim, K.; Jung, J.K.; Kim, Y. An entomopathogenic bacterium, Xenorhabdus hominickii ANU101, produces oxindole and suppresses host insect immune response by inhibiting eicosanoid biosynthesis. J. Invertebr. Pathol. 2017, 145, 13-22. [CrossRef] [PubMed]

13. Sheehan, G.; Clarke, G.; Kavanagh, K. Characterisation of the cellular and proteomic response of Galleria mellonella larvae to the development of invasive aspergillosis. BMC Microbiol. 2018, 18, 63. [CrossRef] [PubMed]

14. Ratcliffe, N.A.; Rowley, A.F. Role of hemocytes in defense against biological agents. In Insect Hemocytes; Gupta, A.P., Ed.; Cambridge University Press: Cambridge, UK, 1979; pp. 331-414.

15. Lemaitre, B.; Hoffmann, J. The host defense of Drosophila melanogaster. Annu. Rev. Immunol. 2007, 25, 697-743. [CrossRef]

16. Galko, M.J.; Krasnow, M.A. Cellular and genetic analysis of wound healing in Drosophila larvae. PLoS Biol. 2004, 2, E239. [CrossRef]

17. Lesch, C.; Jo, J.; Wu, Y.; Fish, G.S.; Galko, M.J. A targeted UAS-RNAi screen in Drosophila larvae identifies wound closure genes regulating distinct cellular processes. Genetics 2010, 186, 943-957. [CrossRef]

18. Theopold, U.; Krautz, R.; Dushay, M.S. The Drosophila clotting system and its messages for mammals. Dev. Comp. Immunol. 2014, 42, 42-46. [CrossRef]

19. Krzemien, J.; Dubois, L.; Makki, R.; Meister, M.; Vincent, A.; Crozatier, M. Control of blood cell homeostasis in Drosophila larvae by the posterior signalling centre. Nature 2007, 446, 325-328. [CrossRef]

20. Markus, R.; Laurinyecz, B.; Kurucz, E.; Honti, V.; Bajusz, I.; Sipos, B.; Somogyi, K.; Kronhamn, J.; Hultmark, D.; Ando, I. Sessile hemocytes as a hematopoietic compartment in Drosophila melanogaster. Proc. Natl. Acad. Sci. USA 2009, 106, 4805-4809. [CrossRef]

21. Dudzic, J.P.; Kondo, S.; Ueda, R.; Bergman, C.M.; Lemaitre, B. Drosophila innate immunity: Regional and functional specialization of prophenoloxidases. BMC Biol. 2015, 13, 81. [CrossRef]

22. Irving, P.; Ubeda, J.M.; Doucet, D.; Troxler, L.; Lagueux, M.; Zachary, D.; Hoffmann, J.A.; Hetru, C.; Meister, M. New insights into Drosophila larval haemocyte functions through genome-wide analysis. Cell Microbiol. 2005, 7, 335-350. [CrossRef] [PubMed]

23. Gregoire, C. Hemolymph coagulation. In The Physiology of Insecta, 2nd ed.; Rockstein, M., Ed.; Academic Press: New York, NY, USA, 1974; Volume 5, pp. 309-360.

24. Osaki, T.; Kawabata, S. Structure and function of coagulogen, a clottable protein in horseshoe crabs. Cell Mol. Life Sci. 2004, 61, 1257-1265. [CrossRef] [PubMed]

25. Iwanaga, S. The limulus clotting reaction. Curr. Opin. Immunol. 1993, 5, 74-82. [CrossRef] 
26. Osaki, T.; Okino, N.; Tokunaga, F.; Iwanaga, S.; Kawabata, S. Proline-rich cell surface antigens of horseshoe crab hemocytes are substrates for protein cross-linking with a clotting protein coagulin. J. Biol. Chem. 2002, 277, 40084-40090. [CrossRef]

27. Iwanaga, S.; Muta, T.; Shigenaga, T.; Miura, Y.; Seki, N.; Saito, T.; Kawabata, S. Role of hemocyte-derived granular components in invertebrate defense. Ann. N. Y. Acad. Sci. 1994, 712, 102-116. [CrossRef]

28. Cerenius, L.; Soderhall, K. Coagulation in invertebrates. J. Innate Immun. 2011, 3, 3-8. [CrossRef]

29. Perdomo-Morales, R.; Montero-Alejo, V.; Perera, E. The clotting system in decapod crustaceans: History, current knowledge and what we need to know beyond the models. Fish Shellfish Immunol. 2019, 84, $204-212$. [CrossRef]

30. Hall, M.; Wang, R.; van Antwerpen, R.; Sottrup-Jensen, L.; Söderhäll, K. The crayfish plasma clotting protein: A vitellogenin-related protein responsible for clot formation in crustacean blood. Proc. Natl. Acad. Sci. USA 1999, 96, 1965-1970. [CrossRef]

31. Sheehan, G.; Garvey, A.; Croke, M.; Kavanagh, K. Innate humoral immune defences in mammals and insects: The same, with differences? Virulence 2018, 9, 1625-1639. [CrossRef]

32. Theopold, U.; Li, D.; Fabbri, M.; Scherfer, C.; Schmidt, O. The coagulation of insect hemolymph. Cell. Mol. Life Sci. 2002, 59, 363-372. [CrossRef]

33. Scherfer, C.; Karlsson, C.; Loseva, O.; Bidla, G.; Goto, A.; Havemann, J.; Dushay, M.S.; Theopold, U. Isolation and Characterization of Hemolymph Clotting Factors in Drosophila melanogaster by a Pullout Method. Curr. Biol. 2004, 14, 625-629. [CrossRef] [PubMed]

34. Karlsson, C.; Korayem, A.M.; Scherfer, C.; Loseva, O.; Dushay, M.S.; Theopold, U. Proteomic analysis of the Drosophila larval hemolymph clot. J. Biol. Chem. 2004, 279, 52033-52041. [CrossRef] [PubMed]

35. Theopold, U.; Samakovlis, C.; Erdjument-Bromage, H.; Dillon, N.; Axelsson, B.; Schmidt, O.; Tempst, P.; Hultmark, D. Helix pomatia lectin, an inducer of Drosophila immune response binds to hemomucin, a novel surface mucin. J. Biol. Chem. 1996, 271, 12708-12715. [CrossRef] [PubMed]

36. Arefin, B.; Kucerova, L.; Dobes, P.; Markus, R.; Strnad, H.; Wang, Z.; Hyrsl, P.; Zurovec, M.; Theopold, U. Genome-wide transcriptional analysis of Drosophila larvae infected by entomopathogenic nematodes shows involvement of complement, recognition and extracellular matrix proteins. J. Innate Immun. 2014, 6, 192-204. [CrossRef] [PubMed]

37. Kucerova, L.; Broz, V.; Arefin, B.; Maaroufi, H.O.; Hurychova, J.; Strnad, H.; Zurovec, M.; Theopold, U. The Drosophila Chitinase-Like Protein IDGF3 Is Involved in Protection against Nematodes and in Wound Healing. J. Innate Immun. 2015. [CrossRef] [PubMed]

38. Wang, Z.; Wilhelmsson, C.; Hyrsl, P.; Loof, T.G.; Dobes, P.; Klupp, M.; Loseva, O.; Morgelin, M.; Ikle, J.; Cripps, R.M.; et al. Pathogen entrapment by transglutaminase-a conserved early innate immune mechanism. PLoS Pathog. 2010, 6, e1000763. [CrossRef]

39. Loof, T.G.; Morgelin, M.; Johansson, L.; Oehmcke, S.; Olin, A.I.; Dickneite, G.; Norrby-Teglund, A.; Theopold, U.; Herwald, H. Coagulation, an ancestral serine protease cascade, exerts a novel function in early immune defense. Blood 2011, 118, 2589-2598. [CrossRef]

40. Myers, A.L.; Harris, C.M.; Choe, K.M.; Brennan, C.A. Inflammatory production of reactive oxygen species by Drosophila hemocytes activates cellular immune defenses. Biochem. Biophys. Res. Commun. 2018, 505, 726-732. [CrossRef]

41. Schmid, M.R.; Dziedziech, A.; Arefin, B.; Kienzle, T.; Wang, Z.; Akhter, M.; Berka, J.; Theopold, U. Insect hemolymph coagulation: Kinetics of classically and non-classically secreted clotting factors. Insect. Biochem. Mol. Biol. 2019, 109, 63-71. [CrossRef]

42. Dziedziech, A.; Schmid, M.; Arefin, B.; Kienzle, T.; Krautz, R.; Theopold, U. Data on Drosophila clots and hemocyte morphologies using GFP-tagged secretory proteins: Prophenoloxidase and transglutaminase. Data Brief 2019, 25, 104229. [CrossRef]

43. Lindgren, M.; Riazi, R.; Lesch, C.; Wilhelmsson, C.; Theopold, U.; Dushay, M.S. Fondue and transglutaminase in the Drosophila larval clot. J. Insect. Physiol. 2008, 54, 586-592. [CrossRef] [PubMed]

44. Shibata, T.; Hadano, J.; Kawasaki, D.; Dong, X.; Kawabata, S.I. Drosophila TG-A transglutaminase is secreted via an unconventional Golgi-independent mechanism involving exosomes and two types of fatty acylations. J. Biol. Chem. 2017, 292, 10723-10734. [CrossRef] [PubMed]

45. Shibata, T.; Kawabata, S.I. Pluripotency and a secretion mechanism of Drosophila transglutaminase. J. Biochem. 2018, 163, 165-176. [CrossRef] [PubMed] 
46. Hyrsl, P.; Dobes, P.; Wang, Z.; Hauling, T.; Wilhelmsson, C.; Theopold, U. Clotting factors and eicosanoids protect against nematode infections. J. Innate Immun. 2011, 3, 65-70. [CrossRef]

47. Bajzek, C.; Rice, A.M.; Andreazza, S.; Dushay, M.S. Coagulation and survival in Drosophila melanogaster fondue mutants. J. Insect. Physiol. 2012, 58, 1376-1381. [CrossRef]

48. Scherfer, C.; Qazi, M.R.; Takahashi, K.; Ueda, R.; Dushay, M.S.; Theopold, U.; Lemaitre, B. The Toll immune-regulated Drosophila protein Fondue is involved in hemolymph clotting and puparium formation. Dev. Biol. 2006, 295, 156-163. [CrossRef]

49. Arneth, B. Coevolution of the coagulation and immune systems. Inflamm. Res. 2019, 68, 117-123. [CrossRef]

50. Papareddy, P.; Kasetty, G.; Alyafei, S.; Smeds, E.; Salo-Ahen, O.M.H.; Hansson, S.R.; Egesten, A.; Herwald, H. An ecoimmunological approach to study evolutionary and ancient links between coagulation, complement and Innate immunity. Virulence 2018, 9, 724-737. [CrossRef]

51. Shokal, U.; Eleftherianos, I. Evolution and Function of Thioester-Containing Proteins and the Complement System in the Innate Immune Response. Front. Immunol. 2017, 8, 759. [CrossRef]

52. Shokal, U.; Kopydlowski, H.; Harsh, S.; Eleftherianos, I. Thioester-Containing Proteins 2 and 4 Affect the Metabolic Activity and Inflammation Response in Drosophila. Infect. Immun. 2018, 86. [CrossRef]

53. Theopold, U.; Schmid, M. Thioester-containing proteins: At the crossroads of immune effector mechanisms. Virulence 2017, 8, 1468-1470. [CrossRef] [PubMed]

54. Toubarro, D.; Avila, M.M.; Hao, Y.; Balasubramanian, N.; Jing, Y.; Montiel, R.; Faria, T.Q.; Brito, R.M.; Simoes, N. A serpin released by an entomopathogen impairs clot formation in insect defense system. PLoS ONE 2013, 8, e69161. [CrossRef] [PubMed]

55. Stanley, D.; Kim, Y. Prostaglandins and Other Eicosanoids in Insects: Biosynthesis and Biological Actions. Front. Physiol. 2018, 9, 1927. [CrossRef] [PubMed]

56. Kim, Y.; Ji, D.; Cho, S.; Park, Y. Two groups of entomopathogenic bacteria, Photorhabdus and Xenorhabdus, share an inhibitory action against phospholipase A2 to induce host immunodepression. J. Invertebr. Pathol. 2005, 89, 258-264. [CrossRef]

57. Park, Y.; Kim, Y. Xenorhabdus nematophilus inhibits p-bromophenacyl bromide (BPB)-sensitive PLA2 of Spodoptera exigua. Arch. Insect. Biochem. Physiol. 2003, 54, 134-142. [CrossRef]

58. Barletta, A.B.F.; Trisnadi, N.; Ramirez, J.L.; Barillas-Mury, C. Mosquito Midgut Prostaglandin Release Establishes Systemic Immune Priming. iScience 2019, 19, 54-62. [CrossRef]

59. Scarpati, M.; Qi, Y.; Govind, S.; Singh, S. A combined computational strategy of sequence and structural analysis predicts the existence of a functional eicosanoid pathway in Drosophila melanogaster. PLoS ONE 2019, 14, e0211897. [CrossRef]

60. Panettieri, S.; Paddibhatla, I.; Chou, J.; Rajwani, R.; Moore, R.; Goncharuk, T.; John, G.; Govind, S. Discovery of aspirin-triggered eicosanoid-like mediators in a Drosophila metainflammation-blood tumor model. J. Cell Sci. 2019. [CrossRef]

61. Haine, E.R.; Rolff, J.; Siva-Jothy, M.T. Functional consequences of blood clotting in insects. Dev. Comp. Immunol. 2007, 31, 456-464. [CrossRef]

62. Krautz, R.; Arefin, B.; Theopold, U. Damage signals in the insect immune response. Front. Plant. Sci. 2014, 5, 342. [CrossRef]

63. Bidla, G.; Hauling, T.; Dushay, M.S.; Theopold, U. Activation of Insect Phenoloxidase after Injury: Endogenous versus Foreign Elicitors. J. Innate Immun. 2009, 1, 301-308. [CrossRef] [PubMed]

64. Keehnen, N.L.P.; Rolff, J.; Theopold, U.; Wheat, C.W. Insect Antimicrobial Defences: A Brief History, Recent Findings, Biases, and a Way Forward in Evolutionary Studies. In Insect Immunity; Ligoxygakis, P., Ed.; Academic Press: Cambridge, MA, USA, 2017; Volume 52, pp. 1-33.

65. Theopold, U.; Schmidt, O. Helix pomatia lectin and annexin V, two molecular probes for insect microparticles: Possible involvement in hemolymph coagulation. J. Insect Physiol. 1997, 43, 667-674. [CrossRef]

66. Lacroix, R.; Dignat-George, F. Microparticles as a circulating source of procoagulant and fibrinolytic activities in the circulation. Thromb. Res. 2012, 129, S27-S29. [CrossRef] [PubMed]

67. Loof, T.G.; Schmidt, O.; Herwald, H.; Theopold, U. Coagulation systems of invertebrates and vertebrates and their roles in innate immunity: The same side of two coins? J. Innate Immun. 2011, 3, 34-40. [CrossRef]

68. Li, D.; Scherfer, C.; Korayem, A.M.; Zhao, Z.; Schmidt, O.; Theopold, U. Insect hemolymph clotting: Evidence for interaction between the coagulation system and the prophenoloxidase activating cascade. Insect. Biochem. Mol. Biol. 2002, 32, 919-928. [CrossRef] 
69. Fiusa, M.M.; Carvalho-Filho, M.A.; Annichino-Bizzacchi, J.M.; De Paula, E.V. Causes and consequences of coagulation activation in sepsis: An evolutionary medicine perspective. BMC Med. 2015, 13, 105. [CrossRef]

70. Simonti, C.N.; Vernot, B.; Bastarache, L.; Bottinger, E.; Carrell, D.S.; Chisholm, R.L.; Crosslin, D.R.; Hebbring, S.J.; Jarvik, G.P.; Kullo, I.J.; et al. The phenotypic legacy of admixture between modern humans and Neandertals. Science 2016, 351, 737-741. [CrossRef]

(C) 2020 by the authors. Licensee MDPI, Basel, Switzerland. This article is an open access article distributed under the terms and conditions of the Creative Commons Attribution (CC BY) license (http://creativecommons.org/licenses/by/4.0/). 